\title{
A Systematic Method for Predictive in-silico Chemical Vapour
}

\section{Deposition}

\author{
Örjan Danielsson ${ }^{1,3}$, Matts Karlsson ${ }^{2}$, Pitsiri Sukkaew ${ }^{1}$, Henrik Pedersen ${ }^{1}$, and Lars Ojamäe ${ }^{1}$ \\ ${ }^{1}$ Department of Physics, Chemistry and Biology, Linköping University, Sweden \\ ${ }^{2}$ Department of Management and Engineering, Linköping University, Sweden \\ ${ }^{3}$ Physicomp AB, Liljanstorpsvägen 20, Västerås, Sweden \\ * e-mail: o.danielsson@physicomp.se
}

\begin{abstract}
A comprehensive systematic method for chemical vapour deposition modelling consisting of seven well defined steps is presented. The method is general in the sense that it is not adapted to a certain type of chemistry or reactor configuration. The method is demonstrated using silicon carbide ( $\mathrm{SiC}$ ) as model system, with accurate matching to measured data without tuning of the model. We investigate the cause of several experimental observations for which previous research only have had speculative explanations. In contrast to previous assumptions, we can show that $\mathrm{SiCl}_{2}$ does not contribute to $\mathrm{SiC}$ deposition. We can confirm the presence of larger molecules at both low and high C/Si ratios, which have been thought to cause so-called step-bunching. We can also show that high concentrations of Si lead to other Si molecules than the ones contributing to growth, which also explains why the $\mathrm{C} / \mathrm{Si}$ ratio needs to be lower at these conditions to maintain high material quality as well as the observed saturation in deposition rates. Due to its independence of chemical system and reactor configuration, the method paves the way for a general predictive CVD modelling tool.
\end{abstract}




\section{Introduction}

Chemical vapour deposition (CVD) processes comprise a vast range of physical and chemical phenomena acting at different time and length scales extending over 10-15 orders of magnitude; from chemical reactions to fluid flow and heat transfer, all influencing the properties and quality of the final coating ${ }^{1}$. This complex interaction, along with the challenges to perform in situ measurements, makes it difficult to obtain a detailed understanding of the CVD process ${ }^{2}$. Thus, developing new processes and/or improving existing ones, are undertaken using experimental trial-and-error methods with the resulting coating as the only measurable output, while the details of the actual deposition mechanism remain largely unknown. Consequently, the CVD process is in many aspects a black box, where tuning of input parameters like precursor flow rates and temperature settings control the final deposition output.

This black box can, however, be unlocked through modelling and simulations that provide detailed information impossible to obtain experimentally ${ }^{2,3}$. Simulation data can often be presented as distributions rather than (a few) points as in the case of measurements and combining simulation data from a complete and detailed model with experimental data enables enhanced analysis possibilities and a deeper understanding, moving towards a knowledge-based process development.

The CVD related phenomena, widely spread in time and length, require different modelling methods found in different disciplines of physics, chemistry and engineering. CVD modelling studies have therefore mainly focused on either the chemistry ${ }^{4,5}$ or the fluid flow characteristics $^{6}$, using simplified descriptions of the other parts of the CVD process. 
Simplified reactor geometries are good in that they can significantly reduce the computational time needed for the simulation. However, in reality, a CVD reactor often has a complex design to facilitate transport and distribution of both precursors and heat to the deposition area. If this design is too much simplified the simulated heat and mass distributions will be significantly different from the real case, giving non-realistic predictions of gas mixture compositions and species concentrations at the deposition surface, ultimately leading to wrong conclusions being drawn from the simulation work.

Simplified descriptions of the chemistry on the other hand, often makes it necessary to introduce some kind of tuning parameter to fit the simulation results to experimental data, leading to a model that predicts what you already know but is less useful for predicting deposition at other process conditions or in a different reactor geometry.

When detailed kinetic models are developed, surprisingly few employ a systematic approach to ensure the model is adequate for its purpose. Two of the earliest and maybe most thorough work on developing reaction mechanisms for CVD were done by Coltrin et $\mathrm{al}^{4}$ for $\mathrm{Si}$ and by Mountziaris and Jensen ${ }^{5}$ for GaAs. Coltrin et $\mathrm{al}^{4}$ constructed a relatively large system of 120 elementary reactions for silane decomposition, which then was reduced to 20 reactions based on a sensitivity analysis. Mountziaris and Jensen ${ }^{5}$ built a reaction mechanism for GaAs consisting of 17 reaction steps based on a combination of equilibrium computations and spectroscopic measurements in specially designed reactors. However, in neither of these studies is the selection of reaction mechanisms fully motivated or explicitly validated.

Many of the studies that have followed, including those for $\mathrm{SiC}^{7,8,9}, \mathrm{AlGaN}^{10}$ and $\mathrm{GaN}^{11}$, are based on either of these two models, with some additions taken from other literature sources. But none of them use a systematic method for selecting which reactions shall be included. This points to the problem: when data from different literature sources are compiled into a 
new model, how can one be sure that the resulting chemical model is accurate and relevant for its purpose?

Here, we present a systematic method for CVD modelling where input kinetic data, from literature or from quantum chemical modelling, is combined with computational fluid dynamics to generate a map of the CVD chemistry that can mimic experimental data without applying correction factors.

\section{A concept for systematic CVD modelling}

A complete model of a CVD process requires detailed descriptions of all phenomena, from the flow of gases, heat generation and distribution, to the chemical reactions in the gas phase and at the surfaces, i.e. a combination of different modelling methods must be used. To enable in-depth studies of CVD through modelling, we suggest a systematic approach as summarized in Table 1, with the details given in the Methods section.

Table 1 A seven-step protocol for systematic CVD modelling

\begin{tabular}{|l|l|}
\hline 1. & Identify controlling phenomena/factors through a system and time scale analysis \\
\hline 2. & $\begin{array}{l}\text { Construct a model for the gas phase reaction mechanisms and determine reaction rate } \\
\text { constants utilizing quantum-chemical (QC) computations or other methods }\end{array}$ \\
\hline 3. & Validate the gas phase kinetic model by performing gas phase kinetics simulations \\
\hline 4. & $\begin{array}{l}\text { Evaluate species concentration trends from the kinetic model and compare with } \\
\text { experiments to determine growth species }\end{array}$ \\
\hline 5. & Construct a surface reaction mechanism and determine reaction rate constants \\
\hline 6. & $\begin{array}{l}\text { Set up and run a simulation of the CVD process using Computational Fluid Dynamics } \\
\text { (CFD), where the gas phase and surface kinetics are included. }\end{array}$ \\
\hline 7. & Validate the CFD model against experiments \\
\hline
\end{tabular}

This comprehensive, yet straight forward, modelling strategy can be used to build robust models independent of reactor geometry, choice of precursors or process conditions. Even 
though some of the individual steps may be well known, and also frequently used in CVD modelling, each step only gives a fraction of the information needed for the full model. Therefore, the order in which each step is performed also becomes important. Our method is constructed so that the information needed for one step is obtained in the previous one. This systematic approach certifies not only that the correct information is used in the model, but also that it is not tuned or adjusted to fit into any predetermined case. Although this might seem obvious, it is not the common way of modelling CVD. Many studies on CVD modelling seen in literature simply starts at step 6 , with no validation or relevance check of the chemical reaction models used ${ }^{12}$.

It should be noted that validation of the surface reaction mechanism between step 5 and step 6 would make sense. However, at present we lack good methods for this, besides checking the resulting growth rate. Therefore, the validation of the surface reaction mechanism is done implicitly via the CFD simulation.

To show the strength and potential of the proposed modelling strategy, it is here applied to CVD of hexagonal silicon carbide ( $\mathrm{SiC})$, a wide bandgap semiconductor material of great importance for the transition to more energy efficient high-power electrical systems ${ }^{13,14}$. As $\mathrm{SiC}$ is a compound material, its CVD process is more complex than that of e.g. silicon, thus increasing the need for modelling as a tool for better understanding. Previous attempts to compile a complete and general model for $\mathrm{SiC}$ CVD are few ${ }^{9,15,16,17}$, and mainly based on the model for heteroepitaxial growth of cubic $\mathrm{SiC}(3 \mathrm{C}-\mathrm{SiC})$ on silicon substrates at $1400^{\circ} \mathrm{C}$ by Allendorf and $\mathrm{Kee}^{8}$, a process quite different from that of homoepitaxial growth of hexagonal $\mathrm{SiC}$ on $\mathrm{SiC}$ substrates at approximately $1600^{\circ} \mathrm{C}$. 


\section{Methods}

Our systematic approach to CVD modelling consists of the seven steps presented above (Table 1).

\subsection{System and time scale analysis}

To find suitable approximations for modelling, one must understand the system, its dominating phenomena and limiting factors. A first overview is obtained via dimensionless numbers that give the ratio between different phenomena. The most useful ones for CVD processes, with typical values, are given in Table 2.

Table 2 Dimensionless numbers to characterise fluid flow and mass transfer in CVD systems.

\begin{tabular}{|c|c|c|}
\hline $\begin{array}{l}\text { Dimensionless } \\
\text { number }\end{array}$ & Description & $\begin{array}{l}\text { Typical values } \\
\text { in CVD }\end{array}$ \\
\hline Reynolds (Re) & $\begin{array}{l}\text { inertial forces vs. viscous forces } \\
\text { laminar to turbulent flow transition for } \operatorname{Re}>2300\end{array}$ & $100-1000$ \\
\hline Nusselt $(\mathrm{Nu})$ & $\begin{array}{l}\text { convective vs. conductive heat transfer } \\
\text { if of the order of } 1 \Rightarrow>\text { laminar flow }\end{array}$ & $1-10$ \\
\hline Knudsen (Kn) & $\begin{array}{l}\text { mean free path vs. physical length scale } \\
\text { if } \gtrsim 1 \text {, the continuum assumption is not valid }\end{array}$ & $<<1$ \\
\hline Prandtl (Pr) & momentum vs. thermal diffusivity & $\sim 1$ \\
\hline Schmidt (Sc) & momentum vs. mass diffusivity & $\sim 1$ \\
\hline Lewis (Le) & thermal vs. mass diffusivity & $\sim 1$ \\
\hline Péclet $\left(\mathrm{Pe}_{\text {mass }}\right)$ & convective mass transfer vs. mass diffusivity & $>100$ \\
\hline Péclet $\left(\mathrm{Pe}_{\text {therm }}\right)$ & convective heat transfer vs. thermal diffusivity & $>100$ \\
\hline Damköhler (Da) & $\begin{array}{l}\text { flow time scale vs. chemical time scale } \\
\text { estimation of the degree of conversion } \\
\text { Da }<0.1=>\text { less than } 10 \% \text { conversion expected. Da }> \\
10=>\text { more than } 90 \% \text { conversion expected. }\end{array}$ & \\
\hline
\end{tabular}

We find that many CVD processes have laminar flows, work in the continuum regime, and that momentum, mass and thermal diffusivities are about equally important. The relation between the flow and chemistry time scales (the Damköhler number) give indications on how to model the chemistry. At high temperatures, gas phase reactions become fast and in comparison, the residence time of the gas in a CVD reactor, i.e. the time for the gas to pass 
through the reactor and during which chemical reactions take place, is orders of magnitude longer. A rough estimate of the residence time is calculated simply by dividing the reactor volume by the volumetric flow, while a more detailed analysis can be made using Computational Fluid Dynamics (CFD) (see Supplement). For a typical CVD process, the Damköhler number is usually very high, indicating that the residence time is important. This does not come as a surprise since the main idea behind CVD is to allow sufficient time for the chemical reactions.

For laminar flow, transport of species towards the surface occurs mainly by diffusion through the fluid flow boundary layer. The time for diffusion, $t_{\text {Diff }}$, can be expressed as

$$
t_{D i f f}=\frac{\lambda_{D i f f}^{2}}{4 D_{i}}
$$

where $D_{i}$ is the mass diffusion coefficient and $\lambda_{\text {Diff }}$ the diffusion length (which could be taken to be equal to the thickness of the boundary layer above the surface, $\delta \approx 4.99 \frac{x}{\sqrt{R e}}$, where $\operatorname{Re}$ is the Reynolds number and $x$ is the distance along the flow direction). The mass diffusion coefficient is

$$
D_{i}=\frac{1-X_{i}}{\sum_{j \neq i} \frac{X_{j}}{D_{i j}}}
$$

Where $X_{i}$ is the molar fraction of species $i$, and $D_{i j}$ is the binary diffusion coefficient given by $^{18}$

$$
D_{i j}=\frac{3}{16} \frac{\sqrt{2 \pi R^{3}}}{N_{a} p \pi} \frac{T^{3 / 2}}{\sigma_{i j}^{2} \Omega_{i j}^{(1,1) *}}\left(\frac{1}{M_{i}}+\frac{1}{M_{j}}\right)^{1 / 2}
$$


$R$ is the gas constant, $N_{a}$ Avogadro's number, $M_{i}$ the molecular mass of species $i, p$ the pressure and $T$ the temperature. $\sigma_{i j}$ is the combined collision diameter of the two species: $\sigma_{i j}=\frac{\sigma_{i}+\sigma_{j}}{2}$, and $\Omega_{i j}^{(1,1) *}$ the collision integral whose values can be found in tables ${ }^{18}$. For diluted mixtures $D_{i} \approx D_{i j}$.

The time for diffusion of adsorbed species on the surface can be estimated by ${ }^{19}$

$$
\tau_{D}=\frac{L^{2}}{16 D_{s}}
$$

Eq. 4

where $L=$ terrace length and $D_{s}=$ surface diffusivity. The surface diffusivity is approximately

$$
D_{s}=v a_{0}^{2} e^{-E_{d} / R T}
$$

where $v=$ lattice vibration frequency (of the order of $10^{12} \mathrm{~Hz}$ ), $a_{0}=$ lattice parameter, $E_{d}=$ diffusion activation energy. $E_{d}$ is approximately half of the bond strength, $E_{d}=0.5 E_{b}$.

\subsection{Gas phase reaction mechanism}

A gas phase reaction mechanism that describe the decomposition of precursors and reactions between by-products is necessary when modelling CVD. A minimum requirement for a general model, that is independent of a specific process or reactor geometry, is to include those species that would be present at thermodynamic equilibrium in the mechanism. Any closed chemical system, held at constant temperature and pressure, will eventually reach a state of thermodynamic equilibrium. Thus, a general reaction mechanism should contain reactions that eventually lead to the equilibrium species. The equilibrium composition is determined through minimization of the Gibbs free energy for a system that allows formation of all species that can be formed by combinations of the atoms contained in the precursors and 
in the carrier gas. When making these calculations there is a risk that the results are biased by the set of molecules chosen for the study, and that wrong conclusions are drawn if the set is too limited. A combinatorial approach can be used to build the set of molecules to be included - molecules made from combinations of atoms from the precursors and the carrier gas. The necessary properties (enthalpy and entropy) of each molecule are then calculated using quantum chemical calculations, or when applicable, found in standard reference databases. For CVD processes it is reasonable to limit the set of molecules to those having a maximum of four or five of the precursor atoms (e.g. hydrocarbons up to $\mathrm{C}_{4} \mathrm{H}_{10}$ or $\mathrm{C}_{5} \mathrm{H}_{12}$ ), since we expect larger molecules to thermally decompose.

When the equilibrium set of species has been determined, the next step is to systematically find reaction paths from common sets of precursors towards these species. This will add several other (intermediate) species to the reaction scheme. Also here, a combinatorial approach can be used as a start to write up the set of reactions, i.e. every type of molecule may react with any other type of molecule. By analysing Gibbs reaction energies, reactions that likely will occur can be found (a negative Gibbs reaction energy indicates that the reaction could proceed spontaneously). Reactions unlikely to occur or reactions leading to highly improbable products, such as very large or unstable molecules, are then removed from the set.

Once the reaction mechanism is set up, the individual reaction rates need to be determined. Transition state theory can be used to derive rate constants for each elementary reaction ${ }^{20}$ and the energy profiles along the reaction coordinates are obtained by quantum-chemical computations. For a reaction with no transition state, the barrier height can be approximated to be equal to the reaction energy when the energy is positive, and to be zero when the energy is negative. 
In our study, all quantum-chemical calculations were done using the Gaussian 09 software ${ }^{21}$. Ground state and transition state structures for each reaction were optimized using the hybrid density functional theory (DFT) B3LYP ${ }^{22,23}$ and Dunning's cc-pVTZ basis set ${ }^{24}$ together with the dispersion energy correction (D3) from Grimme et $\mathrm{al}^{25}$. Harmonic frequencies were calculated at the same level of theory. Transition states were verified by either visualizing the displacement of the imaginary frequencies or by tracing the reaction path from the transition state to the product and reactant states using the intrinsic reaction coordinate (IRC) computation $^{21}$. The electronic energies were calculated using $\operatorname{CCSD}(\mathrm{T})$ single point calculations $^{26,27}$ and cc-pVnZ basis sets from Dunning ${ }^{24,28}$ for $\mathrm{n}=\mathrm{D}, \mathrm{T}$ and $\mathrm{Q}$ before extrapolated to the values at the complete basis set limit using eq. (2) $\mathrm{in}^{29}$.

The choice of QC method has been discussed in the papers ${ }^{30,31}$. The error in the computed activation energies will be reflected in the uncertainties of the rate constants, e.g. an error of $5 \mathrm{~kJ} / \mathrm{mol}$ in the transition state energy would give an error in the rate constant of about $40 \%$ at $1900 \mathrm{~K}$, which should be kept in mind.

For some of the reactions the optimization procedure could not predict any transition state due to a change of the spin states, e.g. the sum of the spin states of the reactants is triplet, while that of the products is singlet. To make accurate calculations of reaction rates for these reactions, more advanced methods are needed, which is beyond the scope of this paper. Instead we used collision theory to determine these reaction rates. The use of collision theory is obviously a simplification, but it can be motivated in cases when the CVD process is mass transport limited, which allows for larger deviations in the reaction rates without altering the overall result. 


\subsection{Validation of the gas phase reaction mechanism}

The final chemical kinetic reaction model should after "infinite" time lead to a gas phase composition equal to the equilibrium state, which means that the equilibrium composition of the gas also can be used to validate the reaction mechanism. Here, we set up a 1D transient model using the reaction mechanism to simulate the evolution of the gas composition with time by numerically integrating the coupled rate law equations of the elementary reaction steps. In practice, this was done using a commercial CFD software, but it could equally well be done via some more specialized software for chemical kinetics, or a relatively simple home-made computer code.

If the validation should fail, it is likely that some reaction paths are missing, and we should go back to step 2 to find additional ones and also make sure there are paths connecting all reacting species.

\subsection{Evaluate species concentration trends to determine growth species}

The number of moles of a species striking the surface per unit area and unit time (impingement rate) is estimated through the commonly used expression derived from the Maxwell-Boltzmann velocity distribution for ideal gases:

$$
\Phi_{i}=\frac{p_{i}}{\sqrt{2 \pi M_{i} R T}}
$$

where $p_{i}$ is the partial pressure of species $i, M_{i}$ its molar mass, $\mathrm{R}$ the gas constant and $\mathrm{T}$ the temperature. The partial pressures are given as results from the kinetic simulations in step 3. For faster computations, one could use thermodynamic equilibrium calculations to obtain the partial pressures, if the reactions are fast enough and residence times are long enough, since we at this stage only are interested in how the species concentrations change (i.e. the trends) 
when varying process conditions and not the exact concentration. Comparing the trends for each species to the variation in deposition rates from experimental data will enable determination of active growth species. It is useful to have access to experimental data covering a broad parameter space for this evaluation.

\subsection{Construct a surface reaction mechanism and calculate/determine reaction rates}

Once the growth species have been determined, surface reaction mechanisms containing these species are constructed similarly as for the gas phase reaction mechanisms.

A common and simple way of describing the reaction rate is by defining a probability for the adsorption, also called sticking coefficient. Then the reaction rate is this probability times the species flux to the surface, i.e. each species that hits the surface will adsorb with a certain probability.

On a general form the surface reaction can be described by

$$
\sum_{i=1}^{N_{g}} \alpha_{i} A_{i}(g)+\sum_{i=1}^{N_{s}} \beta_{i} B_{i}(s)+\sum_{i=1}^{N_{b}} \gamma_{i} C_{i}(b)=\sum_{i=1}^{N_{g}} \alpha_{i}^{\prime} A_{i}(g)+\sum_{i=1}^{N_{s}} \beta_{i}^{\prime} B_{i}(s)+\sum_{i=1}^{N_{b}} \gamma_{i}^{\prime} C_{i}(b) \quad \text { Eq. } 7
$$

where g, s, and b denote gas-phase, surface adsorbed, and bulk (deposited) species, respectively. The rate of the surface reaction is

$$
\dot{S}=k_{f} \prod_{i=1}^{N_{g}}\left[A_{i}(g)\right]_{w}^{\alpha_{i}} \prod_{i=1}^{N_{S}}\left[B_{i}(s)\right]^{\beta_{i}}-k_{r} \prod_{i=1}^{N_{g}}\left[A_{i}(g)\right]_{w}^{\alpha_{i}^{\prime}} \prod_{i=1}^{N_{S}}\left[B_{i}(s)\right]^{\beta_{i}^{\prime}} \quad \text { Eq. } 8
$$

where $k_{f}$ and $k_{r}$ are the forward and reverse rate expressions, and [X] is the molar concentration of molecule X. It is assumed that the reaction rate is independent of the bulk species concentration. 
The rate expressions, often expressed in the Arrhenius form, are calculated using transition state theory and quantum-chemical calculations on cluster models, as described in the supplementary information.

\subsection{Set up and run a simulation of the CVD process using Computational Fluid Dynamics} $\underline{(\mathrm{CFD})}$

Computational Fluid Dynamics (CFD) solves the equations for conservation of mass, momentum and energy at the macroscopic scale by numerical methods. Since most experimental data are measured at the reactor length scale, CFD is a useful method to model CVD processes. The inclusion of gas phase and surface chemical reaction mechanisms in the CFD model is a way to couple the quantum chemistry scale to the reactor continuum scale. Results from the CFD simulation give distributions of deposition, species concentrations, as well as temperatures and flow velocities, which are used for analysing and increasing the understanding of the CVD process.

The concentrations of individual species in the gas are given by

$$
\frac{\partial \rho Y_{i}}{\partial t}+\nabla \cdot\left(\rho \mathbf{v} Y_{i}\right)+\nabla \cdot \mathbf{J}_{\mathrm{i}}=M_{\boldsymbol{i}} \sum_{j=1}^{N_{\text {react }}} v_{i j}\left(R_{j}^{f}-R_{j}^{r}\right)
$$

where $\rho$ is the gas density, $Y_{i}$ the mass fraction of species $i, \mathbf{v}$ the velocity vector, $\mathbf{J}_{\mathrm{i}}$ the diffusive flux, $M_{i}$ the molar mass and $v_{i j}$ the stoichiometric coefficient of species $i$ in reaction $j . R_{j}^{f}$ and $R_{j}^{r}$ are the forward and reverse reaction rates of reaction $j$, respectively. For the simple and general reaction $\alpha \mathrm{A}+\beta \mathrm{B} \rightarrow \mathrm{C}$, the forward reaction rate is

$$
R_{j}^{f}=k_{j}[A]^{\alpha}[B]^{\beta}
$$


where $[\mathrm{A}]$ and $[\mathrm{B}]$ are the concentrations of species $\mathrm{A}$ and $\mathrm{B}$, respectively. $k_{j}$ is the rate constant that e.g. can be calculated by quantum-chemical calculations, see step 2 above. The rate constant is often expressed as an Arrhenius equation, $k_{j}=A T^{n} e^{-E_{a} / R T}$, where $E_{a}$ is the activation energy for the reaction. The reverse reaction rate can be calculated from equilibrium, using

$$
k_{j}^{r}=\frac{k_{j}^{f}}{k_{j}^{e q}}
$$

where

$$
k_{j}^{e q}=\left(\frac{p_{0}}{R T}\right)^{\sum_{i}\left(v_{i}^{\prime \prime}-v_{i}^{\prime}\right)} e^{-\sum_{i}\left(v_{i}^{\prime \prime}-v_{i}^{\prime}\right) \Delta_{r} G_{i}^{0} / R T}
$$

$v_{i}^{\prime \prime}$ and $v_{i}^{\prime}$ are the stoichiometric coefficients of species $i$ on the reactant and product side of the reaction, respectively. $p_{0}$ is the standard state pressure $(100 \mathrm{kPa})$ and $\Delta_{r} G_{i}^{0}$ is the Gibbs free energy change per mole of reaction for unmixed reactants and products at standard conditions.

Reactions at surfaces are implemented in the CFD model as boundary conditions at the solidfluid interfaces. The mass flux to the surface equals the rate at which the gas phase species is consumed by the reaction on the surface. The species flux balance, $J$, for the simple reaction $\alpha \mathrm{A}(\mathrm{g})+\beta \mathrm{B}(\mathrm{s}) \rightarrow$ products is

$$
J=\alpha M R_{a d s}
$$

and the change in surface species concentration is

$$
\frac{d[B(s)]}{d t}=\beta R_{a d s}
$$


The adsorption reaction rate is

$$
R_{a d s}=k_{f}[A(g)]_{w}[B(s)]=k_{f} \frac{\rho_{w} Y_{A, w}}{M_{A}} \rho_{s} X_{B}
$$

where the subscript $w$ indicates the value taken at the wall. The concentration of the species $[A(g)]_{w}=\frac{\rho_{w} Y_{A, w}}{M_{A}}$ and $[B(s)]=\rho_{s} X_{B}$, where $Y_{A}$ is the mass fraction of species $\mathrm{A}$, and $X_{B}$ is the surface site fraction of species B. $\rho_{w}$ is the gas phase density at the surface, $M_{A}$ is the molar mass of species $\mathrm{A}$, and $\rho_{s}$ is the surface site density. The surface site density depends on the crystal structure of the surface and may be calculated from the lattice parameters of the substrate. $k_{f}$ may be written as an Arrhenius expression, $k_{f}=A T^{n} e^{-E_{a} / R T}$, with the units $\left[\frac{m^{3}}{k m o l} \frac{1}{s}\right]$, so that the units of $R_{a d s}$ become $\left[\frac{\mathrm{kmol}}{\mathrm{m}^{2} \mathrm{~s}}\right]$.

For reactions between two adsorbed surface species, the reaction rate is

$$
R_{\text {surf }}=k_{f}\left[B_{1}(s)\right]\left[B_{2}(s)\right]=k_{f} \rho_{s} X_{B 1} \rho_{s} X_{B 2}=k_{f} \rho_{s}^{2} X_{B 1} X_{B 2}
$$

For the reaction to take place, the surface species need to be next to each other, so the expression should in principle take into account the fraction of surface occupied by an adjacent pair of $\mathrm{B}_{1}(\mathrm{~s})+\mathrm{B}_{2}(\mathrm{~s})$, i.e. $X_{B 1+B 2}$. However, we can assume (according to step 1 above) that diffusion on the surface is much faster than the reactions, making the approximation $X_{B 1+B 2}=X_{B 1} \cdot X_{B 2}$ valid. The units of $k_{f}$ are in this case $\left[\frac{m^{2}}{k m o l} \frac{1}{s}\right]$, so that the units of $R_{\text {surf }}$ also become $\left[\frac{\mathrm{kmol}}{\mathrm{m}^{2} \mathrm{~s}}\right]$.

\subsection{Validate the CFD model against experiments}

Experimental data in the literature is not always accompanied by a detailed description of the CVD reactor used, and it could therefore be challenging to set up a CFD model for validation 
even if there is enough deposition data available. Nevertheless, without validation one cannot determine the accuracy and generality of the model, which is necessary if the model shall be used as a predictive tool. Access to own CVD reactors, or close collaboration with a CVD lab could then be crucial. It should be stressed that the CFD model has to be carefully constructed, avoiding simplifications that could affect the simulation results.

The validation could preferably be made in steps; first against temperature (without chemistry added) and then against deposition rates. This is to make sure that the resolution (grid size) of the CFD model and other assumptions are good enough to render accurate temperature results before adding the chemical reactions. If the validation should fail, even if the model can predict the temperature distributions correctly, we should go back to step 5 and re-examine the surface reaction mechanism.

\section{Applying the seven-step protocol: modelling of SiC CVD}

\subsection{System and time scale analysis}

$\mathrm{CVD}$ of semiconductor grade $\mathrm{SiC}$ is performed at around $1600{ }^{\circ} \mathrm{C}$ at reduced pressures around 0.1 bar with precursors, like $\mathrm{SiH}_{4}$ and $\mathrm{C}_{3} \mathrm{H}_{8}$, heavily diluted (concentrations $<1 \%$ ) in the $\mathrm{H}_{2}$ carrier gas. Characterising the fluid flow and mass transfer by dimensionless numbers (Methods) indicate a laminar flow where momentum, thermal and mass diffusivities are about equally important. The residence time of the gas in a typical CVD reactor ${ }^{32}$ is of the order of 0.1 - 1.0 seconds as evaluated by Computational Fluid Dynamics (CFD) (Supplement). A typical value of the diffusion coefficient, $D_{i}$, (calculated from Eq. 2 and Eq. 3 ) is of the order of $10^{-2} \mathrm{~m}^{2} / \mathrm{s}$. With a diffusion length, $\lambda_{\text {Diff, }}$ of the order of millimetres (the thickness of the boundary layer above the surface, i.e. $\delta \approx 4.99 \frac{x}{\sqrt{R e}}$, with $x$ of the order of centimetres and $\operatorname{Re}$ 
of the order of $100-1000)$, the corresponding time for diffusion of species from the gas to the surface, $t_{\text {Diff, }}$, is then of the order of milliseconds. The time for diffusion of adsorbed species, $\tau_{D}$ is in the range $10-1000 \mathrm{~ns}$. These are considerably longer times than the mean time for chemical reactions to occur at the surface. Our model system is therefore mass transport limited when it comes to the actual growth. However, chemical reactions occur all the way along the path towards the growth zone, and the composition of the gas at the growth surface depends on what happens upstream. It is therefore important to model the chemical reactions as accurately as possible.

\subsection{Gas phase reaction mechanism}

The species (end products) that must, as a minimum, be included in the reaction mechanism, are found through calculations of thermodynamic equilibrium for a wide range of temperatures and precursor concentrations, including up to 190 different species (Supplement, Table S1). No condensed phases were allowed to from, a common approach for probing the gas phase composition before it reaches the substrate. At the same time, the larger $\mathrm{Si}$ and $\mathrm{Si}-\mathrm{C}$ molecules (such as $\mathrm{Si}_{6}$ or $\mathrm{Si}_{5} \mathrm{C}$ ) could be thought of as embryos to solid particles in the gas.

The full reaction scheme is constructed from elementary reaction steps that involve precursors, intermediate species and/or end products (Supplement, Table S2-Table S4). For SiC there are three sub-sets of reactions: hydrocarbons, silicon hydrides/chlorides and organosilicons. The hydrocarbon reactions are well studied in previous literature ${ }^{33,34,35,36,37}$, while kinetic reaction rates for the silicon-containing part are calculated using thermodynamic reaction profile results obtained from QC computations (Methods).

In the development of a reaction scheme for $\mathrm{SiC} \mathrm{CVD,} \mathrm{we} \mathrm{made} \mathrm{the} \mathrm{following} \mathrm{considerations:}$ 
- A reaction scheme without $\mathrm{Si}-\mathrm{C}$ molecules will not accurately predict the gas phase composition at "infinite" time. In the literature the reaction schemes for SiC CVD have been decoupled to one silicon side and one carbon side, based on the arguments from Stinespring and Wormhoudt ${ }^{7}$ that the formation of molecules containing both silicon and carbon is unlikely. However, they considered only two different reaction paths $-\mathrm{SiH}_{2}+\mathrm{CH}_{4} \rightarrow \mathrm{H}_{3} \mathrm{SiCH}_{3}$ and $\mathrm{Si}_{2}+\mathrm{CH}_{4} \rightarrow \mathrm{Si}_{2} \mathrm{CH}_{4}-$ and thereby neglected several other possibilities, which are included here.

- For reactions leading to species containing both $\mathrm{Si}$ and $\mathrm{C}$ atoms, we take as reactants those molecules that have high concentrations at standard CVD conditions, i.e. $\mathrm{C}_{2} \mathrm{H}_{2}$, $\mathrm{CH}_{4}, \mathrm{SiH}_{2}$, and $\mathrm{Si}$.

- The reaction $\mathrm{SiH}_{2}+\mathrm{C}_{2} \mathrm{H}_{2} \rightarrow \mathrm{SiC}_{2} \mathrm{H}_{4}$ was suggested $\mathrm{in}^{38}$ where one of the triple bonds in $\mathrm{C}_{2} \mathrm{H}_{2}$ breaks and the $\mathrm{Si}$-atom of the $\mathrm{SiH}_{2}$ is inserted there. A similar situation could be plausible for the gaseous $\mathrm{Si}$ atom: $\mathrm{Si}+\mathrm{C}_{2} \mathrm{H}_{2} \rightarrow \mathrm{SiC}_{2} \mathrm{H}_{2}$ as a first step to form $\mathrm{SiC}_{2}$.

- The SiC CVD process uses large amounts of hydrogen as carrier gas. When chlorinated precursors are used, reactions leading to $\mathrm{HCl}$ are therefore more likely compared to reactions leading to atomic chlorine or chlorine gas.

- At thermodynamic equilibrium, chlorinated carbon species are not found at all, and species containing both $\mathrm{Si}, \mathrm{C}$ plus chlorine have very low concentrations in this environment, at any temperature. They are therefore not considered as important intermediate species. Unless such species are used as precursors (e.g. $\mathrm{CH}_{3} \mathrm{Cl}$ ), their reactions can be excluded.

- Reactions among hydrocarbons are well described in the literature ${ }^{33,34,35,36,37}$. We have chosen to include reactions involving $\mathrm{H}, \mathrm{H}_{2}, \mathrm{CH}_{3}, \mathrm{CH}_{4}, \mathrm{C}_{2} \mathrm{H}_{2}, \mathrm{C}_{2} \mathrm{H}_{3}, \mathrm{C}_{2} \mathrm{H}_{4}, \mathrm{C}_{2} \mathrm{H}_{5}$, $\mathrm{C}_{2} \mathrm{H}_{6}, \mathrm{C}_{3} \mathrm{H}_{6}, \mathrm{i}-\mathrm{C}_{3} \mathrm{H}_{7}, \mathrm{n}-\mathrm{C}_{3} \mathrm{H}_{7}$ and $\mathrm{C}_{3} \mathrm{H}_{8}$. 
The resulting silicon-containing part of the reaction scheme is illustrated in Fig. 1, where the values on the arrows are the Gibbs reaction energies at the process temperature $(\mathrm{T}=1900 \mathrm{~K})$. Some reactions are simplified so that reaction sequences where e.g. two or more $\mathrm{H}_{2}$ molecules split off is represented by a single reaction step. 


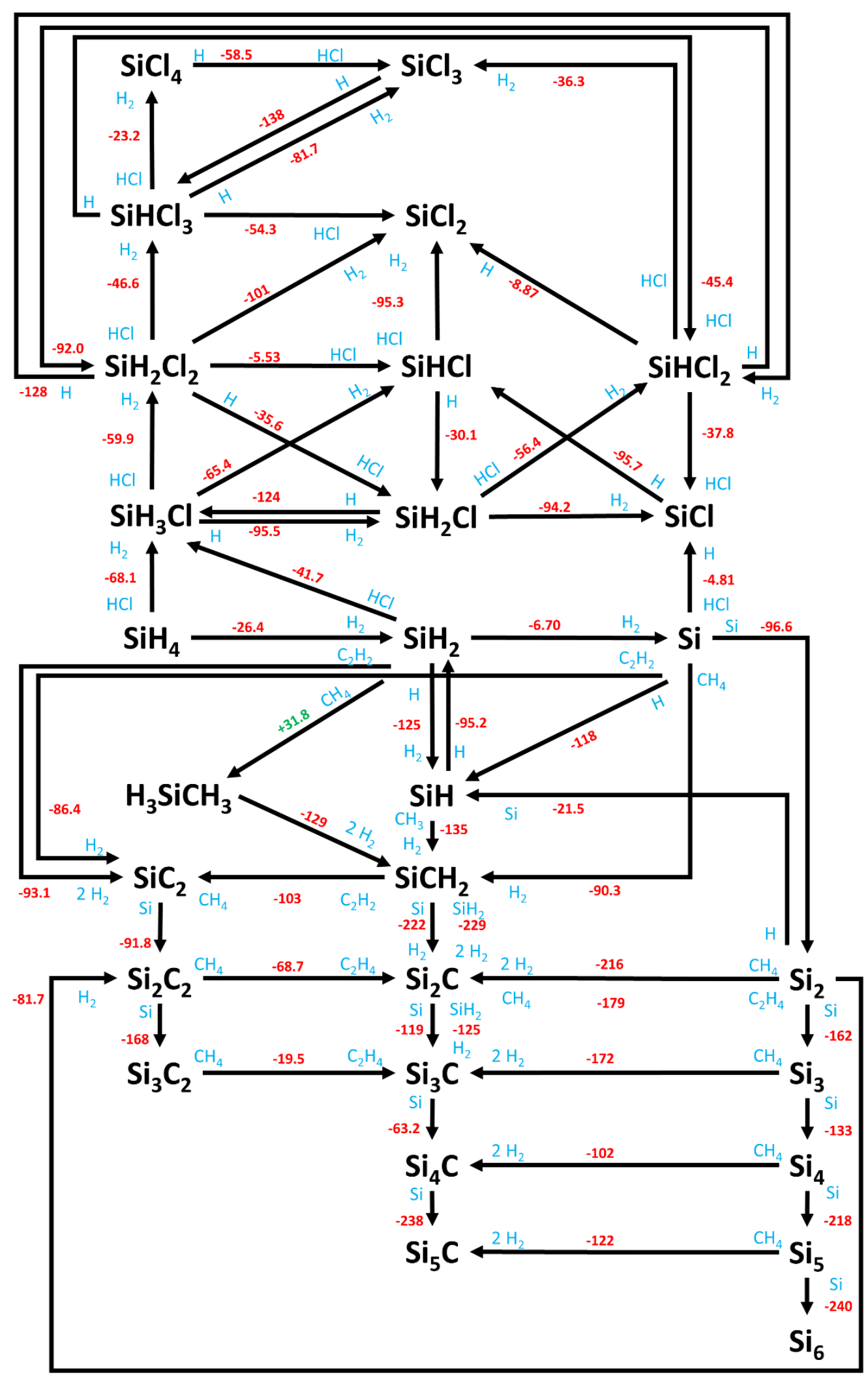

Fig. 1 Proposed reaction scheme for the silicon-containing part in the Si-C-H-Cl system. The values indicated on the arrows are the Gibbs reaction energies at $\mathrm{T}=1900 \mathrm{~K}$. 
The chemical kinetic reaction scheme is validated by performing kinetics simulations, using a one-dimensional transient model to compute the gas phase composition with respect to time at constant temperature and constant pressure. Fig. 2 compares two different sets of precursors for the Si-C-H-Cl chemistry (for the standard Si-C-H chemistry, see Supplement, Fig. S3). After "infinite" time, the model predicts species concentrations close to the equilibrium state, as obtained by independent Gibbs free energy minimization calculations, for all species involved, regardless of precursors. This is very important and shows that, even though the set of species included in the equilibrium calculations was much larger (Supplement, Table S1), the proposed reaction scheme reproduces the gas phase composition at equilibrium, and thus there are no dead-ends or infinite loops in the scheme.

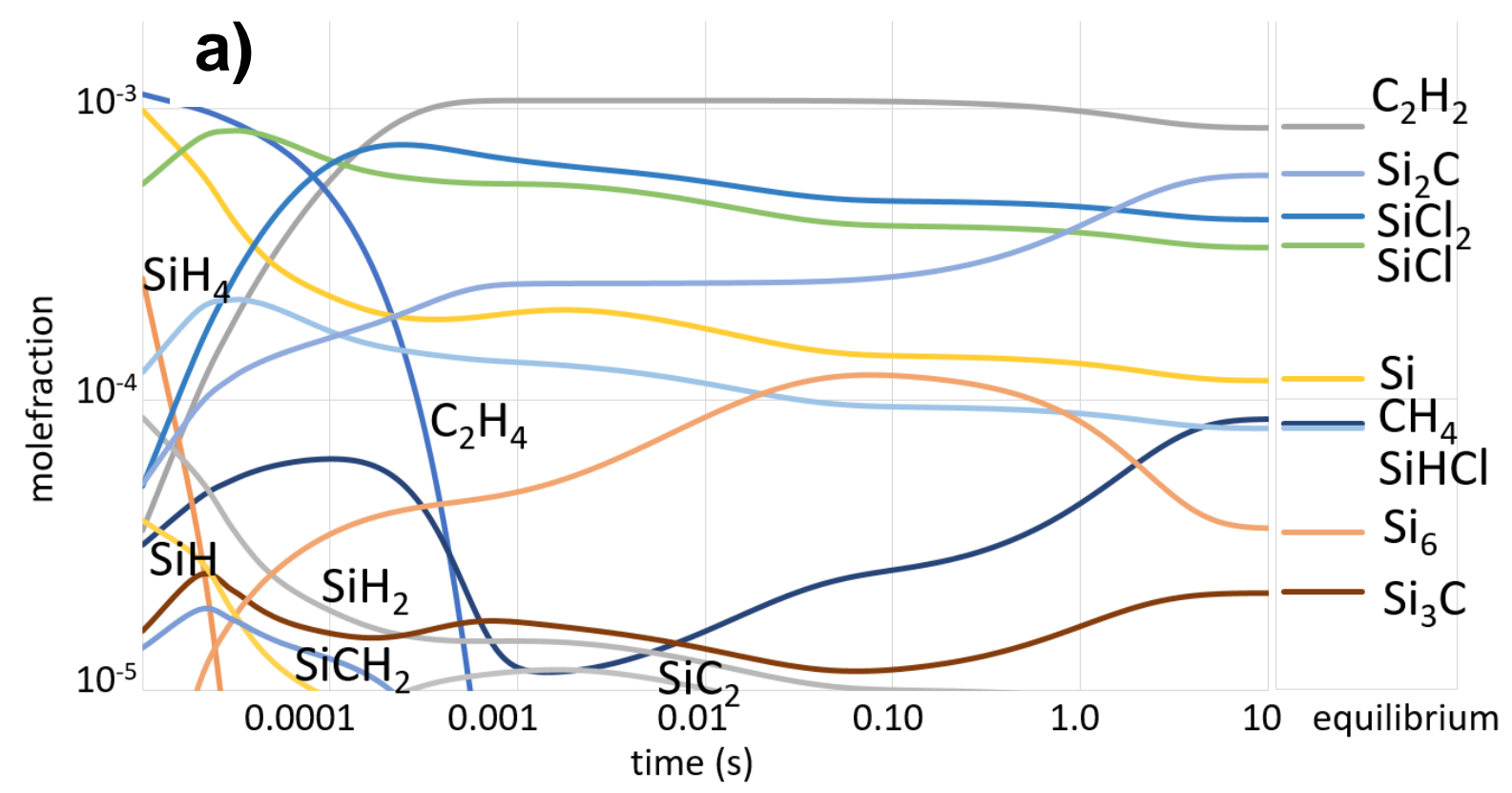




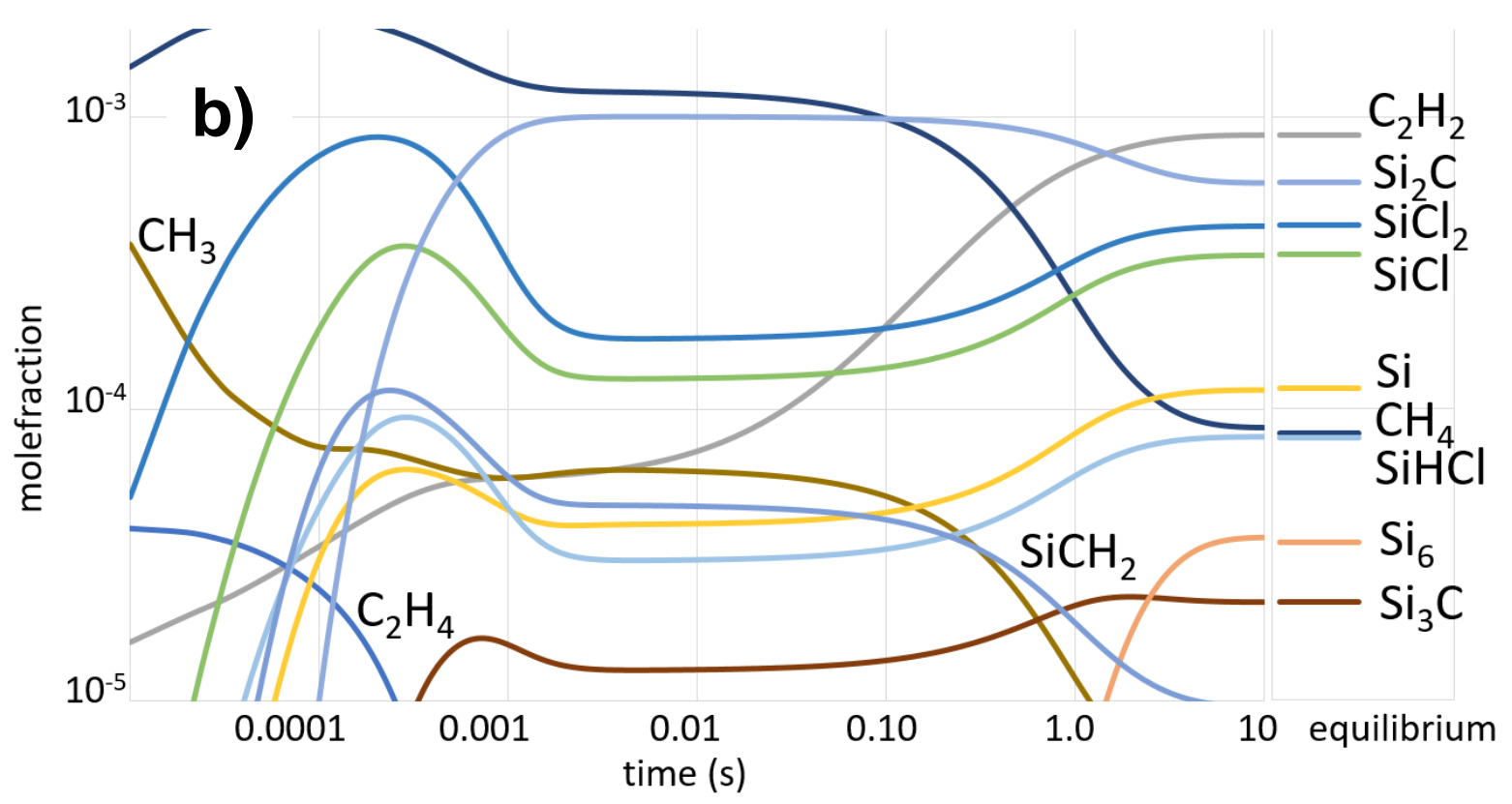

Fig. 2 Species molefraction vs time for a) $\mathrm{C}_{2} \mathrm{H}_{4}+\mathrm{SiH}_{4}+\mathrm{HCl}$ as precursors and b) $\mathrm{C}_{3} \mathrm{H}_{8}+$ $\mathrm{SiCl}_{4}$ as precursors. $\mathrm{T}=1600^{\circ} \mathrm{C}$, total pressure, $\mathrm{p}=100 \mathrm{mbar}$, and partial pressure ratios $\mathrm{Si} / \mathrm{H}_{2}=0.25 \%, \mathrm{C} / \mathrm{Si}=1.0, \mathrm{Cl} / \mathrm{Si}=4$.

Within the timeframe for CVD, i.e. in less than 0.5 seconds, all relevant species reach concentrations of the same order of magnitude as in equilibrium. Hence, for a more extensive analysis of the species concentration trends, equilibrium calculations are used to scan a much larger parameter space of different process conditions, allowing faster calculations and a broader range of process conditions to be analysed. It should be noted that in this way it is only possible to study concentration and relation trends and not the real species concentrations.

\subsection{Evaluate species concentration trends to determine growth species}

For the chemical systems $\mathrm{Si}-\mathrm{C}-\mathrm{H}$ and $\mathrm{Si}-\mathrm{C}-\mathrm{H}-\mathrm{Cl}$, changes in species concentrations with the commonly used experimental parameters temperature, input $\mathrm{C} / \mathrm{Si}$ ratio, input $\mathrm{Cl} / \mathrm{Si}$ ratio and 
input $\mathrm{Si} / \mathrm{H}_{2}$ ratio $^{39}$, are simulated (Fig. 3, and Supplement Fig. S4, Fig. S5 and Fig. S7, respectively). Impingement rates (Methods) are calculated to evaluate the abundance of different species at the growth surface, to explain experimentally observed trends (Table 2) and to find the main growth species.
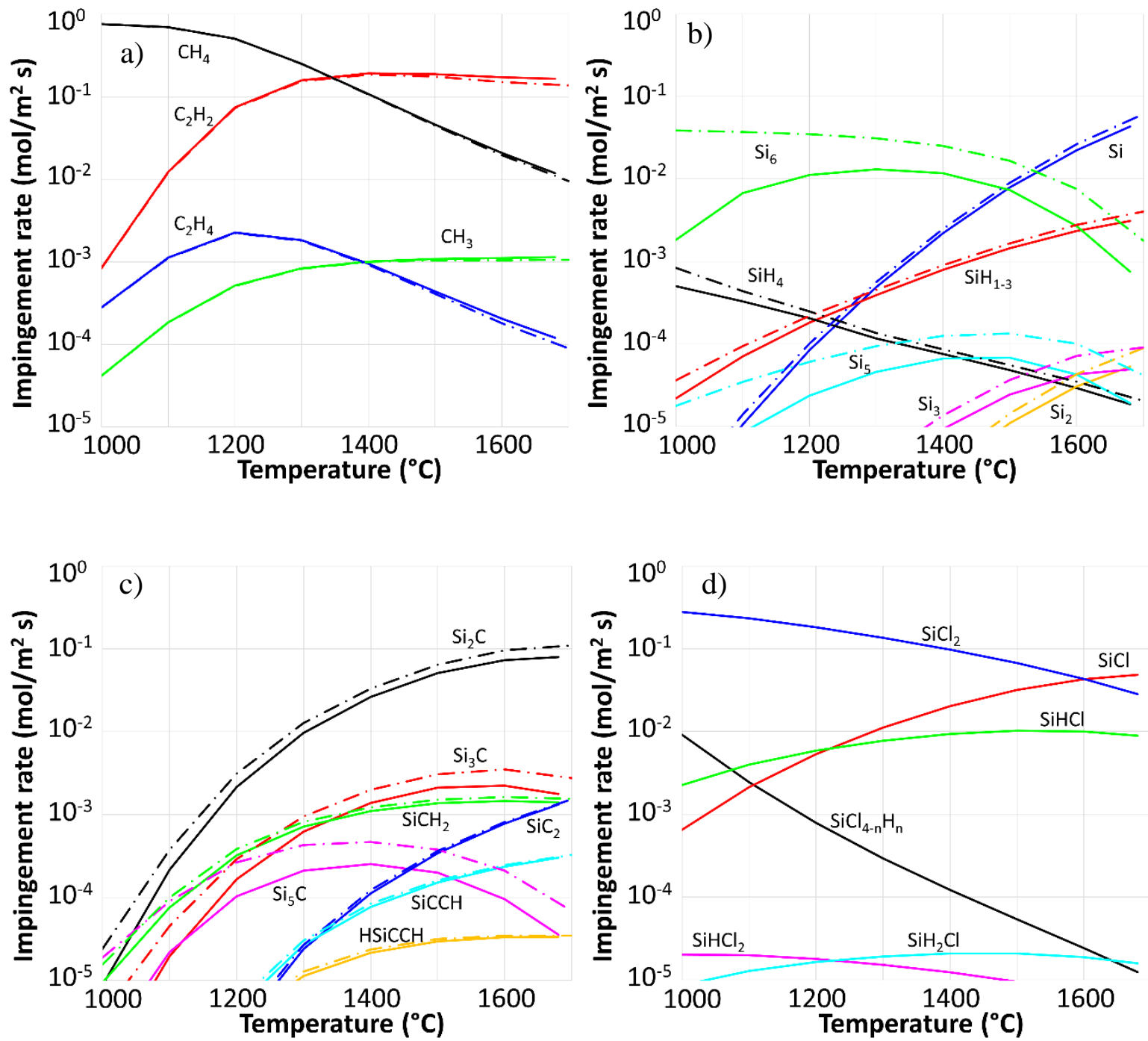

Fig. 3 Impingement rates of the most abundant species at equilibrium in the temperature interval $1000-1700^{\circ} \mathrm{C}$. a) hydrocarbons, b) silicon and silicon hydrides, c) Si-C molecules, and d) silicon-chlorides. For the CVD systems Si-C-H - dash-dotted lines and Si-C-Cl-H solid lines. 
Table 3 Experimental observations and simulated species trends for common experimental parameters.

\begin{tabular}{|c|c|c|}
\hline Parameter & Experimental observation & Simulated species trends \\
\hline $\mathrm{T}$ & $\begin{array}{l}\text { Nitrogen doping is constant for temperatures between } \\
1500-16000^{\circ} \mathrm{C}^{42} \text {, indicating that the concentrations of } \\
\text { active carbon species are constant, or slightly decreasing } \\
\text { to compensate for the higher growth rate. }\end{array}$ & $\begin{array}{l}\mathrm{Si}-\mathrm{C} \text { and } \mathrm{Si}-\mathrm{H} \text { species increase with } \\
\text { temperature. } \\
\mathrm{SiCl}_{2} \text { decrease with temperature. } \\
\mathrm{C}_{2} \mathrm{H}_{2} \text { and } \mathrm{CH}_{3} \text { constant between } \\
1400-1700^{\circ} \mathrm{C} \text {, while } \mathrm{CH}_{4} \text { and } \mathrm{C}_{2} \mathrm{H}_{4} \\
\text { decrease. }\end{array}$ \\
\hline $\mathrm{C} / \mathrm{Si}$ & $\begin{array}{l}\text { High C/Si leads to higher surface roughness }{ }^{43} \text {. } \\
\text { Step bunching occurs both at low and high C/Si - } \\
\text { suggested to be caused by either } \mathrm{Si} \text { or } \mathrm{C} \text { clusters on the } \\
\text { surface }^{44} \text {. }\end{array}$ & $\begin{array}{l}\mathrm{Si}_{3}-\mathrm{Si}_{6}, \text { and } \mathrm{Si}_{n} \mathrm{C}_{\mathrm{m}} \text { decreases with } \\
\text { higher } \mathrm{C} / \mathrm{Si} \text {. } \\
\mathrm{C}_{4} \mathrm{H}_{2} \text { increases to significant levels } \\
\text { at high } \mathrm{C} / \mathrm{Si} \text {. }\end{array}$ \\
\hline $\mathrm{Cl} / \mathrm{Si}$ & $\begin{array}{l}\mathrm{Cl} / \mathrm{Si}>2 \text { is needed to keep good surface morphology } \\
\text { (low surface roughness) - suggested reason is increased } \\
\mathrm{SiCl}_{2} \text { and thereby decreased effective } \mathrm{C} / \mathrm{Si}^{45} \text {. However, } \\
\text { the growth rate decreases with higher } \mathrm{Cl} / \mathrm{Si}-\text { not } \\
\text { matched by potentially increased etching by } \mathrm{HCl}^{46}- \\
\text { indicating less active } \mathrm{Si} \text { species. } \\
\text { Nitrogen doping increases for } \mathrm{Cl} / \mathrm{Si}=2-4^{47} \text {, also } \\
\text { indicating lower } \mathrm{C} / \mathrm{Si} \text {, but then decreases for } \mathrm{Cl} / \mathrm{Si}=3-7 \\
46 \text {. }\end{array}$ & $\begin{array}{l}\text { All } \mathrm{Si}-\mathrm{Cl} \text { species increase with } \\
\text { increasing } \mathrm{Cl} / \mathrm{Si} \text {. SiCl }{ }_{2} \text { increases } \\
\text { more than others do, while } \mathrm{Si}-\mathrm{C} \text { and } \\
\mathrm{Si}-\mathrm{H} \text { species decrease. } \\
\text { Both } \mathrm{C}_{2} \mathrm{H}_{2} / \mathrm{SiCl}_{2} \text { and } \mathrm{C}_{2} \mathrm{H}_{2} / \mathrm{SiCl} \\
\text { ratios decrease over the whole } \\
\text { range } \mathrm{Cl} / \mathrm{Si}=0-8 \text {. } \\
\mathrm{C}_{2} \mathrm{H}_{2} /(\mathrm{Si}+\mathrm{SiCl}) \text { decreases at low } \\
\mathrm{Cl} / \mathrm{Si} \text {, and increases slowly at high } \\
\mathrm{Cl} / \mathrm{Si} \text {, with a minimum at } \mathrm{Cl} / \mathrm{Si}=5 \text {, } \\
\text { which is in fair agreement with the } \\
\text { experiments. }\end{array}$ \\
\hline $\mathrm{Si} / \mathrm{H}_{2}$ & $\begin{array}{l}\text { The growth rate saturates at high } \mathrm{Si} / \mathrm{H}_{2}{ }^{48} \text {. } \\
\text { High } \mathrm{Si} / \mathrm{H}_{2} \text { requires lower } \mathrm{C} / \mathrm{Si} \text { to maintain material } \\
\text { quality }{ }^{49} \text {, and consequently it is suggested that a rough } \\
\text { surface is caused by an increased effective } \mathrm{C} / \mathrm{Si} \text { at } \\
\text { higher } \mathrm{Si} / \mathrm{H}_{2} \text {. } \\
\text { Nitrogen doping decreases more than explained by } \\
\text { higher growth rates }{ }^{42} \text {, i.e. more carbon is competing } \\
\text { with the nitrogen when } \mathrm{Si} / \mathrm{H}_{2} \text { ratio is increased, also } \\
\text { indicating that the "effective" } \mathrm{C} / \mathrm{Si} \text { increases with } \\
\text { increasing } \mathrm{Si} / \mathrm{H}_{2} .\end{array}$ & $\begin{array}{l}\text { Concentrations of } \mathrm{Si} \text { and } \mathrm{SiH}_{1-3} \\
\text { saturates at } \mathrm{Si} / \mathrm{H}_{2}>0.1 \% \text {. } \\
\text { The ratios } \mathrm{C}_{2} \mathrm{H}_{2} / \mathrm{Si} \text { and } \mathrm{C}_{2} \mathrm{H}_{2} / \mathrm{SiH}_{\mathrm{n}} \\
(\mathrm{n}=0-3) \text { increases with increasing } \\
\text { input } \mathrm{Si} / \mathrm{H}_{2} \text {. } \\
\mathrm{C}_{2} \mathrm{H}_{2} / \mathrm{SiCl}_{2} \text { decreases in the whole } \\
\text { range studied. }\end{array}$ \\
\hline
\end{tabular}

$\mathrm{SiCl}_{2}$ has been assumed to be the main active silicon species in $\mathrm{SiC} \mathrm{CVD} \mathrm{with} \mathrm{Cl}$ $\operatorname{addition}^{50,51}$, due to its high concentration at relevant process conditions. Experimentally, the growth rate increases with temperature (i.e. more active $\mathrm{Si}$ species are produced) ${ }^{40,41}$, and decreases with increasing $\mathrm{Cl} / \mathrm{Si}^{41}, 46$, while the concentration of $\mathrm{SiCl}_{2}$ show opposite trends 
(Fig. 3, and Supplement, Fig. S5). Recent findings even suggest a plausible inhibiting effect of halogen atoms ${ }^{52}$. In addition, the effective $\mathrm{C} / \mathrm{Si}$ ratio is shown to increase with higher $\mathrm{Si} / \mathrm{H}_{2}{ }^{49}$, whereas the simulations show an opposite trend for e.g. the ratio $\mathrm{C}_{2} \mathrm{H}_{2} / \mathrm{SiCl}_{2}$ (Supplement Fig. S6). In epitaxial growth of silicon, $\mathrm{SiCl}_{2}$ was also once suggested as the main growth species, but due to its high desorption rate other species are more likely to be the active ones ${ }^{53}$, while $\mathrm{SiCl}_{2}$ remains in the gas phase ${ }^{54,55}$. Based on these results, in contradiction to most previous assumptions, we conclude that $\mathrm{SiCl}_{2}$ does not play a positive role in the $\mathrm{SiC}$ growth process, but rather acts to keep silicon in the gas phase.

Nitrogen is a dopant in $\mathrm{SiC}$ that competes with carbon for the same lattice sites ${ }^{56}$. Thus, changes in doping can be used as an indicator of the active carbon concentration trends, or the effective $\mathrm{C} / \mathrm{Si}$ ratio. In addition, the surface morphology can be used as an indicator of the $\mathrm{C} / \mathrm{Si}$ ratio, as high carbon concentrations result in a rough surface ${ }^{43}$.

Experiments show no or small changes in nitrogen doping and growth rate between $1500^{\circ} \mathrm{C}-$ $1600^{\circ} \mathrm{C}^{42}$. Therefore, the total concentrations of active carbon species should remain constant, or just slightly decrease, in that same range. $\mathrm{CH}_{3}$ and $\mathrm{C}_{2} \mathrm{H}_{2}$, as well as $\mathrm{Si}_{3} \mathrm{C}$ and $\mathrm{SiCH}_{2}$, matches this criterion (Fig. 3). A combination of species with increasing/decreasing concentrations, such as $\mathrm{CH}_{4}+\mathrm{Si}_{2} \mathrm{C}$, could possibly also result in a constant total carbon supply to the growth surface, nonetheless less reactive ${ }^{30}$.

For high silicon concentrations (high $\mathrm{Si} / \mathrm{H}_{2}$ ) the growth rate saturates, while the surface morphology becomes rougher ${ }^{48}$. For chlorinated chemistries, this growth rate saturation occurs at higher $\mathrm{Si} / \mathrm{H}_{2}$, making it possible to obtain higher growth rates. This behaviour is well explained by the simulation results, showing a concentration saturation above $\mathrm{Si} / \mathrm{H}_{2}=0.1 \%$ for $\mathrm{Si}$ and $\mathrm{SiH}_{1-3}$ (Supplement, Fig. $\mathrm{S} 7$ ). SiCl increase throughout the interval studied, and the concentrations level out beyond $\mathrm{Si} / \mathrm{H}_{2}>1.0 \%$. The conclusion is therefore 
that $\mathrm{Si}$ and $\mathrm{SiH}_{1-3}$ are most likely active $\mathrm{Si}$ species, with additional contributions from $\mathrm{SiCl}$ (and possibly $\mathrm{SiHCl}$ ) for the chlorinated chemistry. The active carbon species continue to increase linearly with higher $\mathrm{Si} / \mathrm{H}_{2}$ (when maintaining the input $\mathrm{C} / \mathrm{Si}$ ratio), and thus, the effective $\mathrm{C} / \mathrm{Si}$ ratio increases, eventually causing surface roughening, in accordance with experiments.

Homogeneous gas phase nucleation is assumed to cause silicon droplets deteriorating the surface at high $\mathrm{Si} / \mathrm{H}_{2}{ }^{45}$. In the simulations, the larger $\mathrm{Si}$ species $\left(\mathrm{Si}_{6}\right.$ and $\left.\mathrm{Si}_{5} \mathrm{C}\right)$ increase with higher Si concentrations. These molecules can be said to represent larger clusters of silicon, since we have limited our model to molecules up to this size. Adding chlorine, less $\mathrm{Si}_{6}$ is formed in favour of chlorinated silicon species, thus reducing the risk of gas phase nucleation.

So-called step-bunching has been suggested to be caused by immobile clusters of either carbon or silicon that sits on surface terraces ${ }^{44}$. The highest levels of the larger Si species ( $\mathrm{Si}_{3}$ - $\mathrm{Si}_{6}$ ) occur at low input $\mathrm{C} / \mathrm{Si}$, while one of the larger hydrocarbons included in the study $\left(\mathrm{C}_{4} \mathrm{H}_{2}\right)$ increases to significant levels at high input $\mathrm{C} / \mathrm{Si}$ (see Supplementary material, Fig. S4). Thus, we expect step-bunched growth to be caused by $\mathrm{Si}$ clusters at low $\mathrm{C} / \mathrm{Si}$ ratios, and by $\mathrm{C}$ clusters at high $\mathrm{C} / \mathrm{Si}$ ratios.

\subsection{Construct a surface reaction mechanism and calculate/determine reaction rates}

Based on the conclusions above, the main active growth species are $\mathrm{CH}_{3}, \mathrm{C}_{2} \mathrm{H}_{2}, \mathrm{Si}, \mathrm{SiH}$ and $\mathrm{SiCl}$, possibly with some contributions from $\mathrm{CH}_{4}$ and $\mathrm{Si}_{2} \mathrm{C}$. Reaction mechanisms for adsorption of these species on the $\mathrm{SiC}$ surface were determined using quantum chemical methods based on density functional theory (DFT), and the results have been published elsewhere ${ }^{30,31,57}$. A full surface reaction scheme is given in the Supplement, Table S5. 
For the sake of simplicity here, only adsorption on terraces is accounted for, i.e. adsorption at step edges is not included. It has been observed that the growth rate of $\mathrm{SiC}$ depends on the miscut angle of the substrate ${ }^{58}$. Therefore, further refinements of the surface reaction model to include the effect of step edges, e.g. using the approach used by Yanguas-Gil and Shenai ${ }^{59}$ may improve the accuracy. Also, the model set up here only allow stoichiometric $\mathrm{SiC}$ to form. This means that the Si-rich and C-rich deposition zones that are known to exist will not be accounted for.

\subsection{Set up and run a simulation of the CVD process using Computational Fluid Dynamics} $\underline{(\mathrm{CFD})}$

For a CVD process, the reactor itself may be designed and optimised with the aid of CFD simulations, provided that the desired output parameters can be achieved (e.g. growth rates and distributions). Generally, CFD solves the equations for mass and heat transport by numerical methods. These equations may also include the change in species concentrations by chemical reactions (Methods). A small experimental reactor ${ }^{9}$, for which measured data exists outside the usual sweet spots at the wafer area, was used here as our test model.

\subsection{Validate the CFD model against experiments}

The simulated deposition rates can now be compared to the growth rates measured along the gas flow direction in the entire susceptor ${ }^{9}$, Fig. 4. For the main part of the susceptor, the model is accurately mirroring the experimental results, i.e. growth rates of a few micrometres per hour and a decreasing trend for the growth rate along the gas flow direction. We note that in the experiment the material deposited upstream $(<20 \mathrm{~mm})$ is not considered to be stoichiometric $\mathrm{SiC}$, but rather either Si-rich or C-rich ${ }^{9}$. The present model was simplified and does not consider Si-rich and C-rich deposits, and the effect of a miscut angle of the substrate 
is not included, as pointed out in section 4.5 above. Nevertheless, the obtained growth rates and deposition profile along the gas flow direction are in good agreement with experiments.

It is here worth pointing out that no adjusted parameters have been used - the entire model is systematically built step by step using existing theoretical framework for chemistry and fluid dynamics. The deviation from experiments is reasonable considering the complexity of the process and the uncertainties in both reaction rates (as stated in section 3.2), and the full scale CFD model.

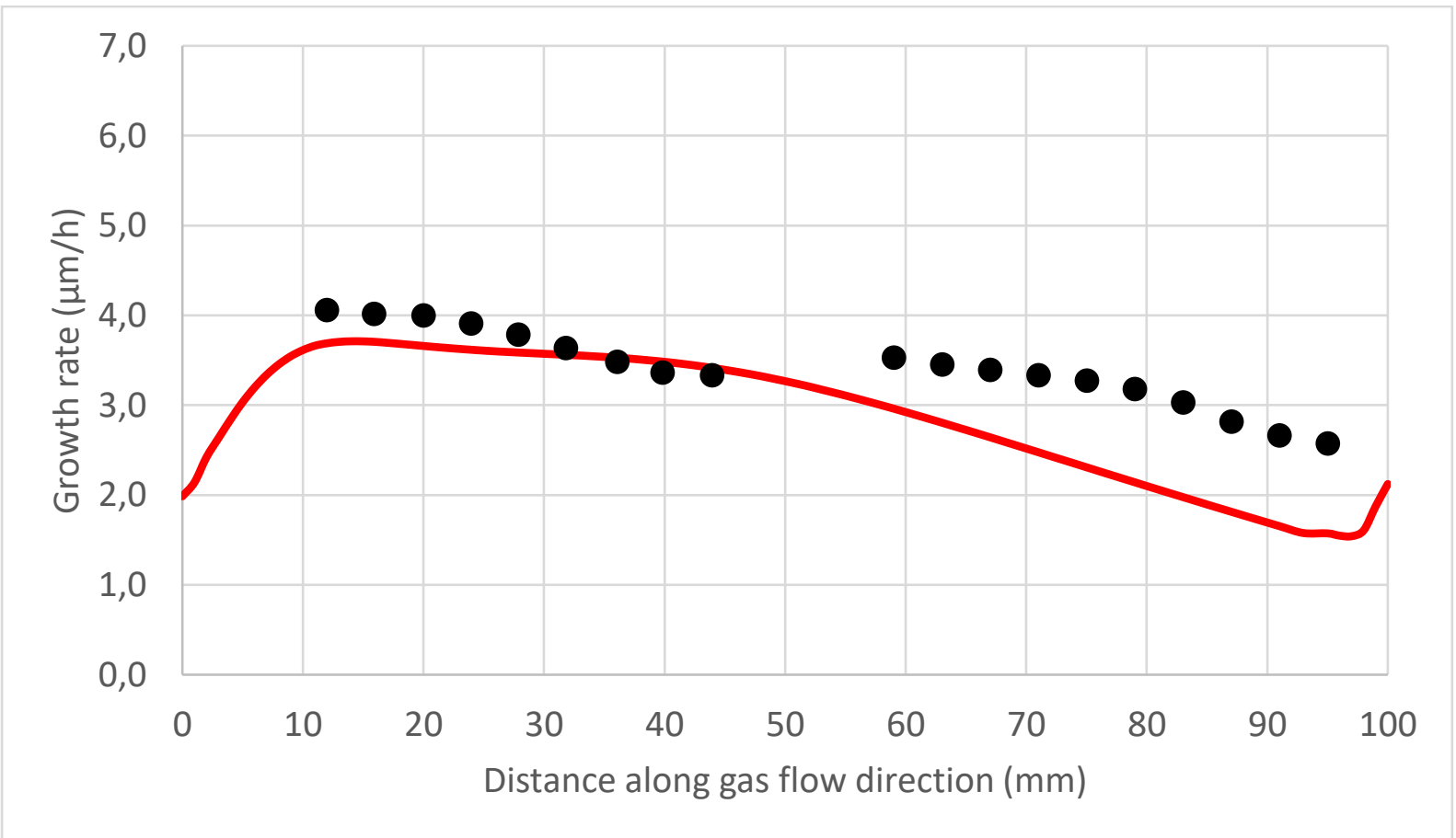

Fig. 4 Growth rate vs. distance along the gas flow direction in a SiC CVD reactor, comparing experiments (black dots) [9] and CFD simulation results (red line). 


\section{Conclusions}

The more complex process to model, the more meticulous one must be setting up the model. However, surprisingly few studies in the literature use a systematic approach when modelling CVD. We have therefore devised a systematic method for in-silico CVD making it possible to perform in-depth studies of any CVD process. Even though the individual steps of the presented method may be well-known, their combined use in the context of CVD modelling has not previously been discussed. The presented method enables creation of models free from tuning parameters that have the potential of being truly predictive tools for next generation materials and processes.

Specifically, applied to CVD of SiC, we have determined the main active growth species for $\mathrm{SiC}$, and species acting as inhibitors to growth. In contrast to previous assumptions, we have shown that $\mathrm{SiCl}_{2}$ does not contribute to $\mathrm{SiC}$ deposition. Further, we have confirmed the presence of larger molecules at both low and high $\mathrm{C} / \mathrm{Si}$ ratios, which have been thought to cause so-called step-bunching. We have also shown that at high enough concentrations of Si, other Si molecules than the ones contributing to growth are formed, which also explains why the $\mathrm{C} / \mathrm{Si}$ ratio needs to be lower at these conditions to maintain high material quality. On the reactor scale we have shown that the thickness distribution can be accurately predicted in comparison to measured data.

The modelling method has already been used to predict the process behaviour for previously untested combinations of precursor gases ${ }^{52}$.

Due to its bottom-up approach and independence of chemical system and reactor configuration, the method paves the way for a general predictive CVD modelling tool for future materials and processes. 


\section{Acknowledgement}

This work was supported by the Swedish Foundation for Strategic Research project "SiC - the Material for Energy-Saving Power Electronics" (EM11-0034) and the Knut \& Alice Wallenberg Foundation (KAW) project "Isotopic Control for Ultimate Material Properties". L.O. acknowledges financial support from the Swedish Government Strategic Research Area in Materials Science on Functional Materials at Linköping University (Faculty Grant SFO Mat LiU No 2009 00971) and from the Swedish Research Council (VR). Supercomputing resources were provided by the Swedish National Infrastructure for Computing (SNIC) and the Swedish National Supercomputer Centre (NSC).

\section{Author contributions}

Ö.D. carried out all kinetic and equilibrium calculations and all CFD simulations, and wrote the manuscript. P.S. and L.O. derived reaction mechanisms, modelled energetics and computed reaction rates based on QC computations and contributed to the evaluations. All authors contributed to interpretation of the results and commented on the manuscript.

\section{Supporting information}

Supplementary material is provided free of charge on the ACS Publications website. The supplement includes reaction rate constants for both the gas phase and surface reactions, and additional results on impingements rates calculated from equilibrium concentrations. 


\section{References}

${ }^{1}$ Choy, K. L. Chemical vapour deposition of coatings, Progress in Materials Science 2003, $48,57-170$.

${ }^{2}$ Pedersen, H.; Elliott, S. D. Studying chemical vapor deposition processes with theoretical chemistry, Theoretical Chemistry Accounts 2014, 133:1476.

${ }^{3}$ Danielsson, Ö.; Sukkaew, P.; Ojamäe, L.; Kordina, O.; Janzén, E. Shortcomings of CVD modeling of SiC today, Theoretical Chemistry Accounts 2013, 132:1398.

${ }^{4}$ Coltrin, M. E.; Kee, R. J.; Miller, J. A. A Mathematical Model of the Coupled Fluid Mechanics and Chemical Kinetics in a Chemical Vapor Deposition Reactor, J. Electrochem. Soc. 1984, 131, 425-434.

${ }^{5}$ Mountziaris, T. J.; Jensen, K. F. Gas-Phase and Surface Reaction Mechanisms in MOCVD of GaAs with Trimethyl-Gallium and Arsine, J. Electrochem. Soc. 1991, 138, 2426-2439. ${ }^{6}$ Moffat, H. K.; Jensen, K. F., Three-Dimensional Flow Effects in Silicon CVD in Horizontal Reactors, J. Electrochem. Soc. 1988, 135, 459-471.

${ }^{7}$ Stinespring, C. D.; Wormhoudt, J. C. Gas Phase Kinetics Analysis and Implications for Silicon Carbide Chemical Vapor Deposition. Journal of Crystal Growth 1988, 87, 481-493.

${ }^{8}$ Allendorf, M. D.; Kee, R. J. A Model of Silicon Carbide Chemical Vapor Deposition. J. Electrochem. Soc. 1991, 138, 841-852.

${ }^{9}$ Danielsson, Ö.; Henry, A.; Janzén, E. Growth Rate Predictions of Chemical Vapor Deposited Silicon Carbide Epitaxial Layers. J. Cryst. Growth 2002, 243, 170-184.

${ }^{10}$ Mihopoulos, T. G.; Gupta, V.; Jensen, K. F., A reaction-transport model for AlGaN MOVPE growth, Journal of Crystal Growth 1998, 195, 733-739. 
${ }^{11}$ Hirako, A.; Kusakabe, K.; Ohkawa, K., Modeling of Reaction Pathways of GaN Growth by Metalorganic Vapor-Phase Epitaxy Using $\mathrm{TMGa} / \mathrm{NH}_{3} / \mathrm{H}_{2}$ System: A Computational Fluid Dynamics Simulation Study, Japanese Journal of Applied Physics 2005, 44, 874-879.

${ }^{12}$ Danielsson, Ö. Understanding the Chemistry in Silicon Carbide Chemical Vapor Deposition, Materials Science Forum 2018, 924, 100-103.

${ }^{13}$ Mitsubishi Electric Corporation, www.mitsubishielectric.com

${ }^{14}$ U.S. Department of Energy, Wide Bandgap Semiconductors for Power Electronics, Quadrennial Technology Review 2015.

${ }^{15}$ Meziere, J.; Ucar, M.; Blanquet, E.; Pons, M.; Ferret, P.; Di Cioccio, L. Modeling and Simulation of SiC CVD in the Horizontal Hot-Wall Reactor Concept. J. Cryst. Growth 2004, $267,436-451$.

${ }^{16}$ Nishizawa, S.-I.; Pons, M. Growth and Doping Modeling of SiC-CVD in a Horizontal HotWall Reactor. Chem. Vap. Deposition 2006, 12, 516-522.

${ }^{17}$ Fiorucci, A.; Moscatelli D.; Masi, M. Homoepitaxial Silicon Carbide Deposition Processes via Chlorine Routes. Surf. Coat. Technol. 2007, 201, 8825-8829.

${ }^{18}$ Hirschfelder, J. O.; Curtiss, C. F; Bird, R. B., Molecular theory of gases and liquids, John Wiley \& Sons, Inc, 1964, ISBN 0-471-40065-3

${ }^{19}$ La Via, F.; Camarda, M.; La Magna, A. Mechanisms of Growth and Defect Properties of Epitaxial SiC. Appl. Phys. Rev. 2014, 1, 031301.

${ }^{20}$ Eyring, H.; M. Polanyi, M. Über einfache gasreaktionen, Z. Phys. Chem. Abt. B 1931, 12, 279-311.

${ }^{21}$ Frisch, M. J.; Trucks, G. W.; Schlegel, H. B.; Scuseria, G. E.; Robb, M. A.; Cheeseman, J. R.; Scalmani, G.; Barone, V.; Mennucci, B.; Petersson, G. A.; et al. Gaussian 09; Gaussian, Inc.: Wallingford, CT, USA, 2009. 
${ }^{22}$ Becke, A. D. Density-functional Thermochemistry. III. The Role of Exact Exchange. $J$. Chem. Phys. 1993, 98, 5648-5652.

${ }^{23}$ Lee, C.; Yang, W.; Parr, R. G. Development of the Colle-Salvetti Correlation-Energy Formula into a Functional of the Electron Density. Phys. Rev. B 1988, 37, 785-789.

${ }^{24}$ Dunning, T. H. Gaussian Basis Sets for Use in Correlated Molecular Calculations. I. The Atoms Boron through Neon and Hydrogen. J. Chem. Phys. 1989, 90, 1007-1023.

${ }^{25}$ Grimme, S.; Antony, J.; Ehrlich, S.; Krieg, H. A Consistent and Accurate Ab Initio Parametrization of Density Functional Dispersion Correction (DFT-D) for the 94 Elements HPu. J. Chem. Phys. 2010, 132 (15), 154104.

${ }^{26}$ Bartlett, R. J. Coupled-Cluster Approach to Molecular Structure and Spectra: A Step toward Predictive Quantum Chemistry. J. Phys. Chem. 1989, 93, 1697-1708.

${ }^{27}$ Raghavachari, K.; Trucks, G. W.; Pople, J. A.; Head-Gordon, M. A Fifth-Order Perturbation Comparison of Electron Correlation Theories. Chem. Phys. Lett. 1989, 157, 479-483.

${ }^{28}$ Woon, D. E.; Dunning, T. H. Gaussian Basis Sets for Use in Correlated Molecular Calculations. III. The Atoms Aluminum through Argon. J. Chem. Phys. 1993, 98, 1358-1371. ${ }^{29}$ Peterson, K. A.; Woon, D. E.; Dunning, T. H. Benchmark Calculations with Correlated Molecular Wave Functions. IV. The Classical Barrier Height of the $\mathrm{H}+\mathrm{H}_{2} \rightarrow \mathrm{H}_{2}+\mathrm{H}$ Reaction. $J$. Chem. Phys. 1994, 100, 7410-7415.

${ }^{30}$ Sukkaew, P.; Danielsson, Ö.; Kordina, O.; Janzén, E.; Ojamäe, L. Ab initio study of growth mechanism of 4H-SiC: Adsorption and surface reaction of $\mathrm{C}_{2} \mathrm{H}_{2}, \mathrm{C}_{2} \mathrm{H}_{4}, \mathrm{CH}_{4}$ and $\mathrm{CH}_{3}$, Journal of Physical Chemistry C 2017, 121, 1249-1256.

${ }^{31}$ Sukkaew, P.; Kalered, E.; Janzén, E.; Kordina, O.; Danielsson, Ö.; Ojamäe, L. Growth mechanism of $\mathrm{SiC}$ chemical vapor deposition: Adsorption and surface reactions of active $\mathrm{Si}$ species, Journal of Physical Chemistry C 2018, 122, 648-661. 
${ }^{32}$ Henry, A.; Hassan, J.; Bergman, J. P.; Hallin, C.; Janzén, E. Thick Silicon Carbide Homoepitaxial Layers Grown by CVD Techniques. Chemical Vapor Deposition 2006, 12, $475-482$

${ }^{33}$ Baulch, D. L.; Cobos, C. J.; Cox, R. A.; Esser, C.; Frank, P.; Just, Th.; Kerr, J. A.; Pilling, M. J.; Troe, J.; Walker, R. W.; Warnatz, J. Evaluated Kinetic Data for Combustion Modelling. J. Phys. Chem. Ref. Data 1992, 21, 411-734.

${ }^{34}$ Tsang, W.; Hampson, R. F. Chemical Kinetic Data Base for Combustion Chemistry. Part I. Methane and Related Compounds. Journal of Physical Chemistry Reference Data 1986, 15, 1087-1279.

35 Tsang, W. Chemical Kinetic Data Base for Combustion Chemistry. Part 3. Propane. Journal of Physical Chemistry Reference Data 1988, 17, 887-951.

${ }^{36}$ Baulch, D. L.; Cobos, C. J.; Cox, R. A.; Frank, P.; Hayman, G.; Just, Th.; Kerr, J. A.; Murrells, T.; Pilling, M. J.; Troe, J.; Walker, R. W.; Warnatz, J. Evaluated Kinetic Data for Combustion Modelling Supplement I. Journal of Physical Chemistry Reference Data 1994, $23,847-1033$.

${ }^{37}$ Baulch, D. L.; Bowman, C. T.; Cobos, C. J.; Cox, R. A.; Just, Th.; Kerr, J. A.; Milling, M. J.; Stocker, D.; Troe, J.; Tsang, W.; Walker, R. W.; Warnatz, J. Evaluated Kinetic Data for Combustion Modeling: Supplement II. Journal of Physical Chemistry Reference Data 2005, $34,757-1397$.

${ }^{38}$ Hong, L-S.; Liu Z-L. Gas-to-particle conversion mechanism in CVD of $\mathrm{SiC}_{\text {by }} \mathrm{SiH}_{4}$ and $\mathrm{C}_{2} \mathrm{H}_{2}$. Ind. Eng. Chem. Res. 1998, 37, 3602-3609.

${ }^{39}$ Pedersen, H.; Leone, S.; Kordina, O. ; Henry, A.; Nishizawa, S.-I.; Koshka Y.; Janzén, E. Chloride-Based CVD Growth of Silicon Carbide for Electronic Applications. Chemical Reviews 2012, 112, 2434-2453. 
${ }^{40}$ Kimoto, T.; Matsunami, H. Surface kinetics of adatoms in vapor phase epitaxial growth of $\mathrm{SiC}$ on $6 \mathrm{H}-\mathrm{SiC}\{0001\}$ vicinal surfaces, Journal of Applied Physics 1994, 75, 850-859.

${ }^{41}$ Leone, S.; Beyer, F. C.; Pedersen, H.; Andersson, S.; Kordina, O.; Henry, A.; Janzén, E. Chlorinated Precursor Study in Low Temperature Chemical Vapor Deposition of 4H-SiC. Thin Solid Films 2011, 519, 3074-3080.

${ }^{42}$ Forsberg, U.; Danielsson, Ö.; Henry, A.; Linnarsson, M. K.; Janzén, E. Nitrogen Doping of Epitaxial Silicon Carbide. Journal of Crystal Growth 2002, 236, 101-112.

${ }^{43}$ Yazdanfar, M.; Ivanov, I. G.; Pedersen, H.; Kordina, O.; Janzén, E. Reduction of Structural Defects in Thick 4H-SiC Epitaxial Layers Grown on $4^{\circ}$ Off-Axis Substrates. Journal of Applied Physics 2013, 113, 223502.

${ }^{44}$ Ishida, Y.; Takahashi, T.; Okumura, H.; Arai, K.; Yoshida, S. Origin of Giant Step Bunching on 4H-SiC (0001) Surfaces. Mater. Sci. Forum 2009, 600-603, 473-476.

${ }^{45}$ La Via, F.; Camarda, M.; La Magna, A. Mechanisms of Growth and Defect Properties of Epitaxial SiC. Applied Physics Review 2014, 1, 031301.

${ }^{46}$ Karhu, R.; Booker, I.; Ul Hassan, J.; Ivanov, I.; Janzén, E. The Role of Chlorine During High Growth Rate Epitaxy. Material Science Forum 2015, 821-823, 141-144.

${ }^{47}$ Pedersen, H.; Beyer, F. C.; Hassan, J.; Henry, A.; Janzén, E. Donor incorporation in SiC Epilayers Grown at High Growth Rate With Chloride Based CVD, Journal of Crystal Growth 2009, 311, 1321-1327.

48 Tanaka, T.; Kawabata, N.; Mitani, Y.; Sakai, M.; Tomita, N.; Tarutani, M.; Kuroiwa, T.; Toyoda, Y.; Imaizumi, M.; Sumitani. H.; Yamakawa, S. Influence of Growth Pressure and Addition of $\mathrm{HCl}$ Gas on Growth Rate of 4H-SiC Epitaxy. Material Science Forum 2015, 821$823,133-136$.

${ }^{49}$ La Via, F.; Izzo, G. Camarda, M.; Abbondanza, G.; Crippa, D. Thick Epitaxial Layer Growth by Chlorine Addition, Material Science Forum 2009, 615-617, 55-60. 
${ }^{50}$ Veneroni, A.; Omarini, F.; Masi, M. Silicon Carbide Growth Mechanisms from $\mathrm{SiH}_{4}$, $\mathrm{SiHCl}_{3}$ and $\mathrm{nC}_{3} \mathrm{H}_{8}$. Crystal Research Technology 2005, 40, 967-971.

${ }^{51}$ Wang, R.; Ma, R.; Dudley, M. Reduction of Chemical Reaction Mechanism for HalideAssisted Silicon Carbide Epitaxial Film Deposition. Industrial \& Engineering Chemistry Research 2009, 48, 3860-3866.

${ }^{52}$ Stenberg, P.; Danielsson, Ö.; Erdtman, E.; Sukkaew, P.; Ojamäe, L.; Janzén, E.; Pedersen, H. Matching precursor kinetics to afford a more robust CVD chemistry: a case study of the C chemistry for silicon carbide using $\mathrm{SiF}_{4}$ as precursor, Journal of Material Chemistry C. 2017, $5,5818-5823$.

${ }^{53}$ Coon, P. A.; Wise, M. L.; George, S. M. Modeling silicon epitaxial growth with $\mathrm{SiH}_{2} \mathrm{Cl}_{2}$, Journal of Crystal Growth 1993, 130, 162-172.

${ }^{54}$ Valente, G.; Cavallotti, C.; Masi, M.; Carrà, S. Reduced order model for the CVD of epitaxial silicon from silane and chlorosilanes, Journal of Grystal Growth 2001, 230, 247 257.

${ }^{55}$ Mayangsari, T. R.; Yusup, L. L.; Park, J-M.; Blanquet, E.; Pons, M.; Jung, J.; Lee, W-J. Study of surface reaction during selective epitaxy growth of silicon by thermodynamic analysis and density functional theory calculation, Journal of Crystal Growth 2017, 468, 278 282.

${ }^{56}$ Larkin, D. J.; Neudeck, P. G.; Powell, J. A.; Matus, L. G. Site-Competition Epitaxy for Superior Silicon Carbide Electronics. Applied Physics Letters 1994, 65, 1659-1661.

${ }^{57}$ Sukkaew, P.; Danielsson, Ö.; Ojamäe, L. Growth mechanism of SiC CVD: Surface etching by $\mathrm{H}_{2}, \mathrm{H}$ atoms, and $\mathrm{HCl}$, Journal of Physical Chemistry A 2018, 122, 2503-2512.

${ }^{58}$ Matsunami, H.; Kimoto, T. Step-controlled epitaxial growth of SiC: High quality homoepitaxy, Materials Science and Engineering: R: Reports 1997, 20(3), 125-166. 
${ }^{59}$ Yanguas-Gil, A.; Shenai, K. Thermodynamics and Kinetics of SiC CVD Epitaxy, ECS

Transactions 2014, 64(7), 133-143. 